\title{
Drought stress enhances nutritional and bioactive compounds, phenolic acids and antioxidant capacity of Amaranthus leafy vegetable
}

\author{
Umakanta Sarker ${ }^{1,2^{*}}$ and Shinya Oba ${ }^{1}$
}

\begin{abstract}
Background: Bioactive compounds, vitamins, phenolic acids, flavonoids of A. tricolor are the sources of natural antioxidant that had a great importance for the food industry as these detoxify ROS in the human body. These natural antioxidants protect human from many diseases such as cancer, arthritis, emphysema, retinopathy, neuro-degenerative cardiovascular diseases, atherosclerosis and cataracts. Moreover, previous literature has shown that drought stress elevated bioactive compounds, vitamins, phenolics, flavonoids and antioxidant activity in many leafy vegetables. Hence, we study the nutritional and bioactive compounds, phenolic acids, flavonoids and antioxidant capacity of amaranth under drought stress for evaluation of the significant contribution of these compounds in the human diet.

Results: The genotype VA3 was assessed at four drought stress levels that significantly affected nutritional and bioactive compounds, phenolic acids, flavonoids and antioxidant capacity. Protein, ash, energy, dietary fiber, Ca, K, $\mathrm{Cu}, \mathrm{S}, \mathrm{Mg}, \mathrm{Mn}, \mathrm{Mo}, \mathrm{Na}, \mathrm{B}$ content, total carotenoids, TFC, vitamin C, TPC, TAC (DPPH), betacarotene, TAC (ABTS ${ }^{+}$), sixteen phenolic acids and flavonoids were remarkably increased with the severity of drought stress. At moderate and severe drought stress conditions, the increments of all these components were more preponderant. Transcinnamic acid was newly identified phenolic acid in A. tricolor. Salicylic acid, vanilic acid, gallic acid, chlorogenic acid, Trans-cinnamic acid, rutin, isoquercetin, $m$-coumaric acid and $p$-hydroxybenzoic acid were the most abundant phenolic compounds in this genotype.
\end{abstract}

Conclusions: In A. tricolor, drought stress enhanced the quantitative and qualitative improvement of nutritional and bioactive compounds, phenolic acids, flavonoids and antioxidants. Hence, farmers of semi-arid and dry areas of the world could be able to grow amaranth as a substitute crop.

Keywords: Amaranthus tricolor, Nutritional and bioactive compounds, Phenolics, Flavonoids, Antioxidant activity, HPLC-UV, LC-MS-ESI, DPPH, ABTS+, Drought

\footnotetext{
* Correspondence: umakanta@bsmrau.edu.bd

${ }^{1}$ The United Graduate School of Agricultural Science, Laboratory of Field

Science, Faculty of Applied Biological Sciences, Gifu University, Yanagido 1-1,

Gifu, Japan

2Department of Genetics and Plant Breeding, Faculty of Agriculture,

Bangabandhu Sheikh Mujibur Rahman Agricultural University, Gazipur 1706,

Bangladesh
}

(c) The Author(s). 2018 Open Access This article is distributed under the terms of the Creative Commons Attribution 4.0 International License (http://creativecommons.org/licenses/by/4.0/), which permits unrestricted use, distribution, and reproduction in any medium, provided you give appropriate credit to the original author(s) and the source, provide a link to the Creative Commons license, and indicate if changes were made. The Creative Commons Public Domain Dedication waiver (http://creativecommons.org/publicdomain/zero/1.0/) applies to the data made available in this article, unless otherwise stated. 


\section{Background}

Both researchers and consumers have much interests to natural antioxidants of vegetables. These natural compounds protect many diseases, such as cancer, arthritis, emphysema, retinopathy, neuro-degenerative and cardiovascular diseases, atherosclerosis, and cataracts [1-4]. Amaranthus tricolor is an inexpensive and excellent source of lots of natural antioxidants like nutritional and bioactive compounds, phenolics, flavonoids and detoxifies reactive oxygen species (ROS) in human body [2, 5].

The intensity of damage caused by reactive oxygen species (ROS) mainly depends on its balance between production and elimination by the antioxidant scavenging system [6]. Moreover, drought stress favors rapid damage and leakage of plant cell membrane [6]. Environmental stresses cause oxidative damage in the plant. Stressed-plants have also protection systems to overcome the oxidative damage by synthesis of secondary metabolites like phenolics, flavonoids [7, 8]. These compounds can detoxify ROS in plants, and also have the capacity to cure many human diseases caused by oxidative damage and aging [9].

Amaranths can tolerate drought efficiently [10, 11]. A. tricolor is a well-acclimated leafy vegetable against biotic and abiotic stresses [12] and had multipurpose usages. Many processes, such as environmental, biological, ecological, physiological, biochemical and evolutionary process are involved in the quantitative and qualitative improvement of natural antioxidants of this species of which, drought stress can rapidly boost up the contents [13].

There is limited information on leafy vegetables regarding the effect of secondary metabolites to drought stress, such as nutritional and bioactive compounds, phenolics, flavonoids and antioxidants. Drought stress enhanced secondary metabolites, such as betacarotene composition in Choysum varieties [14] and in perennial herbaceous [15], vitamin $\mathrm{C}$ in tomato [16], total polyphenol and total flavonoid content in buckwheat [17], total antioxidant activity, total polyphenol and total flavonoid content in Achillea species [18]. On the other hand, drought stress declined buckwheat's protein composition [17], betacarotene composition of Kailaan variety [14] and vitamin C, $\mathrm{Zn}, \mathrm{Ca}$ and Fe content of both varieties [14]. There is no literature regarding drought stress effects on nutritional and bioactive compounds, phenolics, flavonoids and antioxidant activity in $A$. tricolor. Our earlier studies [19-26], we selected some antioxidants enriched and high yielding genotypes. Consequently, the study was aimed to evaluate the drought stress effects on selected genotype for nutritional and bioactive compounds, phenolics, flavonoids and antioxidant activity.

\section{Methods}

Experimental site, plant materials and experimental conditions

Earlier, we collected 102 genotypes in different eco-geographical zones of the country. From this collection, an antioxidant enriched high yield potential genotype (Accession VA3) was selected based on our previous studies [19-26]. This genotype was grown in pots under rain shelter open field of Bangabandhu Sheikh Mujibur Rahman Agricultural University, Bangladesh (AEZ-28, 24 $23^{\circ}$ ' north latitude, 90 $08^{\circ}$ east longitude, 8.4 m.s.l.). $22 \mathrm{~cm}$ height and $24 \mathrm{~cm}$ diameter (upper side) plastic pots were used to raise the seedlings. For pots preparation, soil and cow dung were mixed @ 2:1 ratio. For proper germination and dynamic seedling growth, pots were properly irrigated every day up to 10 days after sowing of seeds (DAS). At first, field capacity of soil used in pots was measured by the gravimetric method. Then the amount of water at $100 \%$ field capacity was measured by subtracting the weight of completely dry soil from the weight of soil at $100 \%$ field capacity. Pot weight (including pot soil) for each treatment was calculated by weighing of completely dry soil and amount of water required for attaining respective field capacity. Pots were irrigated at $100 \%$ field capacity up to 5 days after planting (DAP) for dynamic growth and proper establishment of seedlings. After establishment period, A. tricolor plants were subjected to the different irrigation treatments as FC (100\% field capacity, control), mild stress (90\% FC), moderate stress $(60 \%$ FC), and severe stress (30\% FC). Throughout cultivation period, moisture levels in the soil were controlled by daily weighting following the standard procedure. Pots were weighed twice a day at $12 \mathrm{~h}$ intervals. To achieve the target field capacity of each water condition, the amount of water equaling that lost through transpiration and soil evaporation, percolation and leaching were added. Imposition of water stress was continued up to 30 DAP. At 30 DAP the leaves of $A$. tricolor were harvested from each experimental unit. All the parameters were measured in three replicates.

\section{Chemicals}

Solvent: methanol and acetone. Reagents: Standard compounds of pure phenolic acids, HPLC grade acetonitrile and acetic acid, vitamin $C$, gallic acid, rutin, methanol, DPPH (2,2-diphenyl-1-picryl-hydrazyl), ABT$\mathrm{S}^{+}$(2,2-azinobis-3-ethyl-enzothiazoline-6-sulphonicacid), trolox (6-hydroxy-2,5,7,8-tetra-methyl-chroman-2-carboxylicacid), aluminum chloride hexa-hydrate, sodium carbonate, potassium acetate, Folin-Ciocalteu reagent, $\mathrm{H}_{2} \mathrm{SO}_{4}, \mathrm{NaOH}, \mathrm{HNO}_{3}, \mathrm{HClO}_{4}$, lanthamum, Caesium chloride, dithiothreitol (DTT) and potassium persulfate. 
The pure and analytical grade solvents and reagents from Kanto Chemical Co. Inc. (Tokyo, Japan) and Merck (Germany) were used in this experiment.

\section{Proximate composition}

ASAE standards were followed to determine the moisture content [27]. A. tricolor leaves were dried in an oven at $103{ }^{\circ} \mathrm{C}$ for $72 \mathrm{~h}$. The dried leaves were then transferred to a desiccator for cooling at room temperature. The leaves were then weighted in a digital balance (Denver Instruments, Denver, Colorado, USA) to record the sample weight.

AOAC methods were followed to measure ash, crude fat, and crude protein contents [28]. Leaf samples were weighed before and after heat treatment $\left(550{ }^{\circ} \mathrm{C}\right.$ for $12 \mathrm{~h}$ ) to measure the ash content. AOAC method 960.39 was followed to measure the crude fat content.

Total nitrogen content was measured according to the micro-Kjeldahl method. Finally, total nitrogen was converted to crude protein multiplied by the factor 6.25 (AOAC method 976.05). Fiber was determined by ISO method 5498 [29]. At first, $0.255 \mathrm{M}$ sulfuric acid was added to the leaf powder sample and boiled for $30 \mathrm{~min}$. The insoluble residue was filtered, washed, and boiled in $0.313 \mathrm{M}$ sodium hydroxide. Finally, it was dried at $130 \pm$ $2{ }^{\circ} \mathrm{C}$ for $2 \mathrm{~h}$. At $350 \pm 25{ }^{\circ} \mathrm{C}$ temperature and the weight loss was determined. Fiber content was measured relative to the fresh weight (FW). By subtracting the sum of percent moisture, ash, crude fat, and crude protein from 100, carbohydrate content (g $100 \mathrm{~g}^{-1}$ FW) was measured. A bomb calorimeter was used to determine gross energy following ISO method 9831.

\section{Estimation of mineral content}

At first, $A$. tricolor leaves were dried in a well-ventilated oven at $60{ }^{\circ} \mathrm{C}$ for $24 \mathrm{~h}$. Dried leaves were ground finely in a mill. Nitric-perchloric acid digestion methods were used to determine the minerals contents, such as $\mathrm{Ca}$, $\mathrm{Mg} \mathrm{K}, \mathrm{P}, \mathrm{S}, \mathrm{Fe}, \mathrm{Mn}, \mathrm{Cu}, \mathrm{Zn}, \mathrm{Na}, \mathrm{Mo}$ and $\mathrm{B}$ from powdered leaves [30]. For nitric-perchloric acid digestion, $0.5 \mathrm{~g}$ dried leaves were added to $400 \mathrm{ml}$ of nitric acid (65\%) with $40 \mathrm{ml}$ of perchloric acid (70\%) and $10 \mathrm{ml}$ of sulphuric acid (96\%) in the presence of carborundum beads. After digestion, $\mathrm{P}$ was measured by appropriately diluting the solution in triplicate following vitamin $\mathrm{C}$ method. Addition of vitamin $\mathrm{C}$ and $\mathrm{Sb}$, yellow-colored complex converted to a blue-colored phosphomolybdenum complex. Absorbance was taken according to the method described by Sarker \& Oba [31] at wavelength of $880 \mathrm{~nm}(\mathrm{P}), 766.5 \mathrm{~nm}(\mathrm{~K}), 422.7 \mathrm{~nm}(\mathrm{Ca}), 285.2 \mathrm{~nm}$ (Mg), $258.056 \mathrm{~nm}(\mathrm{~S}), 248.3 \mathrm{~nm}(\mathrm{Fe}), 279.5 \mathrm{~nm}(\mathrm{Mn})$, $324.8 \mathrm{~nm}(\mathrm{Cu}), 213.9 \mathrm{~nm}(\mathrm{Zn}), 589.0 \mathrm{~nm}(\mathrm{Na}), 313.3 \mathrm{~nm}$ (Mo) and $430 \mathrm{~nm}$ (B) by atomic absorption spectrophotometry (AAS) (Hitachi, Tokyo, Japan).

\section{Estimation of betacyanin and betaxanthin content}

Fresh amaranth leaves were used to extract betacyanin and betaxanthin using $80 \%$ methanol containing $50 \mathrm{mM}$ vitamin C according to Sarker \& Oba [31]. Hitachi U1800 spectrophotometer (Hitachi, Tokyo, Japan) was used to measure the absorbance of betacyanin and betaxanthin at 540 and $475 \mathrm{~nm}$, respectively. The mean molar extinction coefficients for betacyanin and betaxanthin were $62 \times 10^{6} \mathrm{~cm}^{2} \mathrm{~mol}^{-1}$ and $48 \times 10^{6} \mathrm{~cm}^{2} \mathrm{~mol}^{-1}$ respectively. Data were recorded as ng betanin $\mathrm{g}^{-1}$ of leaves fresh weight for betacyanin and ng indicaxanthin $\mathrm{g}^{-1}$ of $\mathrm{A}$. tricolor leaves fresh weight for betaxanthin.

\section{Estimation of chlorophyll and total carotenoids}

The fresh A. tricolor leaves were used to estimate chlorophylls and total carotenoids using $80 \%$ acetone following Sarker \& Oba's [32] method. Hitachi U1800 spectrophotometer (Hitachi, Tokyo, Japan) was used to read the absorbance at 663, 646 and $470 \mathrm{~nm}$ for chlorophyll $a$, chlorophyll $b$ and total carotenoids, respectively. Chlorophylls were measured as $\mu \mathrm{g}$ per $\mathrm{g}$ fresh weight and carotene was measured as mg total carotenoids per $100 \mathrm{~g}$ fresh weight.

\section{Estimation of betacarotene}

Betacarotene were measured following the method Sarker \& Oba [31]. $500 \mathrm{mg}$ of fresh leaves were ground in $10 \mathrm{ml}$ of $80 \%$ acetone. The extracts were centrifuged at $10,000 \mathrm{rpm}$ for 3-4 min. Removing the supernatant, $20 \mathrm{ml}$ was transported to a volumetric flask. Hitachi U1800 spectrophotometer (Hitachi, Tokyo, Japan) was used to read the absorbance at $510 \mathrm{~nm}$ and $480 \mathrm{~nm}$, respectively. Results were recorded as mg betacarotene per $g$ fresh weight.

The betacarotene content was calculated using the following formula:

$$
\begin{aligned}
\text { Amount of betacarotene } & =7.6(\text { Abs.at } 480)-1.49(\text { Abs.at } 510) \\
& \times \text { Final volume } \\
& /(1000 \times \text { fresh weight of leaf taken })
\end{aligned}
$$

\section{Determination of vitamin C}

Vitamin C (AsA) and dehydroascorbate (DHA) acid were measured spectrophotometrically. Dithiothreitol (DTT) was used to pre-incubate the sample for reduction of DHA into AsA. $\mathrm{Fe}_{3}{ }^{+}$were reduced to $\mathrm{Fe}_{2}{ }^{+}$by AsA and the spectrophotometric (Hitachi, U-1800, Tokyo, Japan) determination of AsA was performed by measuring $\mathrm{Fe}_{2}{ }^{+}$complexes with 2, 2-dipyridyl [31]. Hitachi U1800 spectrophotometer (Hitachi, Tokyo, Japan) was used to read the absorbance of the sample 
solution at $525 \mathrm{~nm}$. Results were recorded as $\mathrm{mg}$ vitamin $\mathrm{C}$ per $100 \mathrm{~g}$ fresh weight.

\section{Extraction of samples for total polyphenol, flavonoid content and antioxidant activity analysis}

At the edible stage (35 days after sowing) leaves were picked and dried in air (In shade) for total polyphenol content, total antioxidant activity and total flavonoid content analysis. $1 \mathrm{~g}$ of air-dried leaves from each treatment was ground and extracted in $40 \mathrm{ml}$ of $90 \%$ aqueous methanol in a tightly capped bottle $(100 \mathrm{ml})$. The bottle was then placed in a shaking water bath (Thomastant T-N22S, Thomas Kagaku Co. Ltd., Japan) for 1 h. For analysis of total polyphenol content, total antioxidant activity and total flavonoid content the extract was then filtered and stored.

\section{Estimation of total polyphenol content (TPC)}

The Folin-Ciocalteu reagent method described by Sarker \& Oba [31] was used to measure the total phenolic content of amaranth leaves. Gallic acid was used as a standard phenolic compound. $1 \mathrm{ml}$ of Folin-Ciocalteu reagent (previously diluted 1:4, reagent: distilled water) and $50 \mu \mathrm{l}$ of the leaf extract were placed in a test tube, finally mixed thoroughly and allowed to stand for $3 \mathrm{~min}$. Then, $1 \mathrm{ml}$ of $\mathrm{Na}_{2} \mathrm{CO}_{3}$ (10\%) was added, and the mixture allowed to stand for $1 \mathrm{~h}$ in the dark. Hitachi U1800 spectrophotometer (Hitachi, Tokyo, Japan) was used to read the absorbance at $760 \mathrm{~nm}$. A standard gallic acid graph was used as a standard reference to estimate the total polyphenol content in the leaf extracts. The results are recorded as $\mu \mathrm{g}$ gallic acid equivalent (GAE) $\mathrm{g}^{-1} \mathrm{dw}$.

\section{Estimation of total flavonoid content (TFC)}

Aluminum chloride colorimetric method described by Sarker \& Oba [31] was used to estimate the total flavonoid content in leaves extract. $1.5 \mathrm{ml}$ of methanol, $0.1 \mathrm{ml}$ of $1 \mathrm{M}$ potassium acetate, $0.1 \mathrm{ml}$ of $10 \%$ aluminum chloride, $500 \mu \mathrm{l}$ of leaf extract and $2.8 \mathrm{ml}$ of distilled water were transferred to a test tube and allowed to stand for $30 \mathrm{~min}$ at room temperature. Hitachi U1800 spectrophotometer (Hitachi, Tokyo, Japan) was used to read the absorbance at $415 \mathrm{~nm}$. Rutin was used as the standard compound. Total flavonoid content was recorded as $\mu \mathrm{g}$ rutin equivalent $(\mathrm{RE}) \mathrm{g}^{-1} \mathrm{dw}$.

\section{Estimation of total antioxidant capacity (TAC)}

The diphenyl-picrylhydrazyl (DPPH) radical degradation method [31] was used to estimate the antioxidant activity. $10 \mu \mathrm{l}$ of leaf extract solution, $4 \mathrm{ml}$ of distilled water and $1 \mathrm{ml}$ of $250 \mu \mathrm{M}$ DPPH solution were placed in a test tube. The tube was mixed thoroughly and allowed to stand for $30 \mathrm{~min}$ in the dark. Hitachi U1800 spectrophotometer (Hitachi, Tokyo, Japan) was used to read the absorbance at $517 \mathrm{~nm}$. The antioxidant activity $\left(\mathrm{ABTS}^{+}\right)$ was measured following the method of Sarker \& Oba [31]. Separately, 7.4 mM ABTS ${ }^{+}$solution and $2.6 \mathrm{mM}$ potassium persulfate solution were prepared to make two different stock solutions. Two stock solutions were mixed in equal quantities to prepare the working solution and allowed to react for $12 \mathrm{~h}$ at room temperature in the dark. A $2850 \mu \mathrm{l}$ of $\mathrm{ABTS}^{+}$solution $\left(1 \mathrm{ml} \mathrm{ABTS}{ }^{+}\right.$ solution mixed with $60 \mathrm{ml}$ methanol) was allowed to react with $150 \mu \mathrm{l}$ of leaf extract for $2 \mathrm{~h}$ in the dark. Hitachi U1800 spectrophotometer (Hitachi, Tokyo, Japan) was used to read the absorbance at $734 \mathrm{~nm}$. The antioxidant activity was calculated as the percent of inhibition of $\mathrm{DPPH}$ and $\mathrm{ABTS}^{+}$relative to the control using the following equation:

$$
\begin{aligned}
& \text { Antioxidant activity }(\%) \\
& =(\text { Absorbance of blank-Absorbance of sample } \\
& \text { / Absorbance blank }) \times 100
\end{aligned}
$$

Where, Absorbance blank is the absorbance of the control reaction $[10 \mu \mathrm{l}$ methanol for TAC (DPPH), $150 \mu \mathrm{l}$ methanol for TAC $\left(\mathrm{ABTS}^{+}\right)$instead of leaf extract] and Absorbance sample is the absorbance of the test compound. Trolox was used as the reference standard, and the results were expressed as $\mu \mathrm{g}$ trolox equivalent $\mathrm{g}^{-1} \mathrm{dw}$.

\section{Extraction of samples for HPLC and LC-MS analysis}

$1 \mathrm{~g}$ of leaves were homogenized with $10 \mathrm{ml}$ of $80 \%$ methanol containing $1 \%$ acetic acid and filtered through a $0.45 \mu \mathrm{m}$ filter using a MILLEX $-\mathrm{HV}$ syringe filter (Millipore Corporation, Bedford, MA, USA) by the method of Khanam et al. [33]. The filtrate was centrifuged at $10,000 \mathrm{~g}$ for $15 \mathrm{~min}$ and used to analyze phenolic acids and flavonoids.

\section{HPLC analysis of phenolic acids and flavonoids}

HPLC method described by Khanam et al. [33] was used to estimate the amounts of phenolic acids and flavonoids in amaranth leaves. LC-10Avp binary pumps, a degasser (DGU-14A) and a variable Shimadzu SPD-10Avp UVvis detector were equipped to the HPLC system (Shimadzu SCL10Avp, Kyoto, Japan). Phenolic acids and flavonoids were separated through a CTO-10 AC (STR ODS-II, $150 \times 4.6 \mathrm{~mm}$ I.D., Shinwa Chemical Industries, Ltd., Kyoto, Japan) column. The binary mobile phase consisted of $6 \%(\mathrm{v} / \mathrm{v})$ acetic acid in water (solvent A) and acetonitrile (solvent B) was pumped at a flow rate of $1 \mathrm{ml} / \mathrm{min}$ for a total run time of $70 \mathrm{~min}$. The system was run with a gradient program: $0-15 \%$ B for $45 \mathrm{~min}, 15-$ $30 \% \mathrm{~B}$ for $15 \mathrm{~min}, 30-50 \% \mathrm{~B}$ for $5 \mathrm{~min}$ and $50-100 \% \mathrm{~B}$ 
for $5 \mathrm{~min}$. The injection volume was $10 \mathrm{ml}$ while the column temperature was maintained at $35{ }^{\circ} \mathrm{C}$. For simultaneous monitoring of hydroxybenzoic acids, hydroxycinnamic acids and flavonoids, the detector was set at 254, 280 and $360 \mathrm{~nm}$, respectively. The retention time and UV-vis spectra with those of standards were used to compare the identified compound. Mass spectrometry was also used to confirm the phenolic acids and flavonoids qualitatively. The sum of contents of HPLC quantified phenolic acids and flavonoids was denoted as the total phenolic index (TPI). Khanam et al. [33] method was used to obtain TPI. In each estimation, two samples were prepared for all analysis. The results were recorded as $\mu \mathrm{gg}^{-1}$ fresh weight (FW).

The Mass spectrometry analyses were performed in negative ion mode using a JEOL AccuTOF (JMS-T100LP, JEOL Ltd., Tokyo, Japan) mass spectrometer. It was then fitted with an Agilent 1100 Series HPLC system and a UV-vis detector coupled on-line with an ElectroSpray Ionization (ESI) source. The column elute were recorded in the range of $\mathrm{m} / \mathrm{z} 0-1000$. Needle voltage was kept at 2000 V. To obtain chromatograms with good resolution of adjacent peaks, a slight modification was made in the method reported by Khanam et al. [33] by optimizing the chromatographic conditions. LC-MS-ESI analysis was used to identify extract constituents.

\section{Statistical analysis}

The results were described as the mean \pm SD of three samples $(n=3)$ in each replication. Analysis of variance was performed by using Statistix 8 software. The mean separation was compared by the Duncan's Multiple Range Test (DMRT) at $1 \%$ level of probability.

\section{Results}

Influence of nutritional compositions to drought stress Effects of nutritional compositions under different drought stress of $A$. tricolor are presented in Fig. 1. Control and low drought stress (LDS) condition exhibited the highest moisture content, while the moisture content was gradually decreased from moderate drought stress (MDS) to severe drought stress (SDS). Moisture content was drastically reduced with the increase of drought stress in the order: (control > LDS > MDS > SDS). SDS condition had the highest protein, ash, and dietary fiber content, while the lowest protein, ash, and dietary fiber content were observed under the control condition. Protein, ash and dietary fiber content were remarkably increased with an increase in the severity of drought stress in the following order: control $<$ LDS $<$ MDS $<$ SDS. In LDS, MDS and SDS, protein, ash and dietary fiber content were augmented by (17, 17 and 4\%); (80, 29 and 21\%) and (118, 38 and 28\%); respectively over control condition (Fig. 2).
MDS condition had the highest fat content, and the lowest fat content was recorded at SDS condition, while the intermediate fat content was noticed under control and LDS conditions. Control condition had the highest carbohydrates content and it was gradually decreased in the order: control > LDS > MDS = SDS, which was statistically similar to MDS and SDS, respectively. Carbohydrate content was sharply declined with the severity of drought stress. The energy ranged from 34.67 to $45.61 \mathrm{~g}$ $100 \mathrm{~g}^{-1}$ with the highest energy was recorded in SDS and the lowest in LDS condition.

\section{Drought stress effects on mineral content}

Results of minerals (macro and microelements) contents are presented in Figs. 3, 4. The mineral contents of $A$. tricolor were progressively influenced by drought stress. $\mathrm{Ca}, \mathrm{K}, \mathrm{Na}, \mathrm{Mg}, \mathrm{S}, \mathrm{Cu}$ and Mo content were statistically similar under control and LDS conditions, whereas $\mathrm{Ca}$, $\mathrm{Mg}, \mathrm{K}, \mathrm{S}, \mathrm{Cu}, \mathrm{Na}$ and Mo content were sharply and remarkably augmented with the severity of drought stress from MDS and SDS conditions showing the order: control $=\mathrm{LDS}<\mathrm{MDS}<\mathrm{SDS}$.

In MDS and SDS, $\mathrm{Ca}, \mathrm{K}, \mathrm{S}, \mathrm{Mg}, \mathrm{Na}, \mathrm{Cu}$ and Mo content were augmented by $(46,19,14,25,148,13$ and $119 \%)$ and (103, 61, 29, 86, 215, 26 and 200\%), respectively compared to control and LDS conditions (Fig. 5). B and $\mathrm{Mn}$ content were statistically increased with the increase of drought stress in the order: control $<\mathrm{LDS}<$ MDS $<$ SDS. In LDS, MDS and SDS, the rate of increase of $\mathrm{Mn}$ and $\mathrm{B}$ were $(22 \%, 8 \%),(71 \%, 23 \%)$ and $(121 \%$, $37 \%$ ), respectively, over control condition (Fig. 5). Further, it was noted that, increasing drought stress lead to a significant decrease in $\mathrm{P}$ content in the following order: control > LDS > MDS > SDS. In LDS, MDS and SDS, reduction of $\mathrm{P}$ was $3 \%, 18 \%$ and $32 \%$, respectively, over control condition (Fig. 5). Statistically, there were no significant differences in Fe and $\mathrm{Zn}$ content under control and LDS conditions, whereas Fe and Zn content were significantly and drastically declined with the severity of drought stress from MDS and SDS conditions showing the order: control $=$ LDS $>$ MDS $>$ SDS. In MDS and SDS, Fe and $\mathrm{Zn}$ content were reduced by (8\%, 5\%) and $(17 \%, 13 \%)$, respectively compared to control and LDS conditions (Fig. 5). The highest $\mathrm{Ca}, \mathrm{Mg}, \mathrm{K}, \mathrm{S}, \mathrm{Mn}$, $\mathrm{Cu}, \mathrm{Na}, \mathrm{Mo}$ and $\mathrm{B}$ content were observed in SDS, while the lowest $\mathrm{Ca}, \mathrm{Mg}, \mathrm{K}, \mathrm{S}, \mathrm{Mn}, \mathrm{Cu}, \mathrm{Na}, \mathrm{Mo}$ and $\mathrm{B}$ content were found in control or LDS condition. Conversely, the highest $\mathrm{P}, \mathrm{Fe}$ and $\mathrm{Zn}$ content were recorded in control or LDS condition and the lowest P, Fe and $\mathrm{Zn}$ content were found in SDS.

\section{Drought stress effects on leaf pigments}

Leaf pigments of vegetable amaranth were significantly affected by drought stress (Fig. 6). Except total 


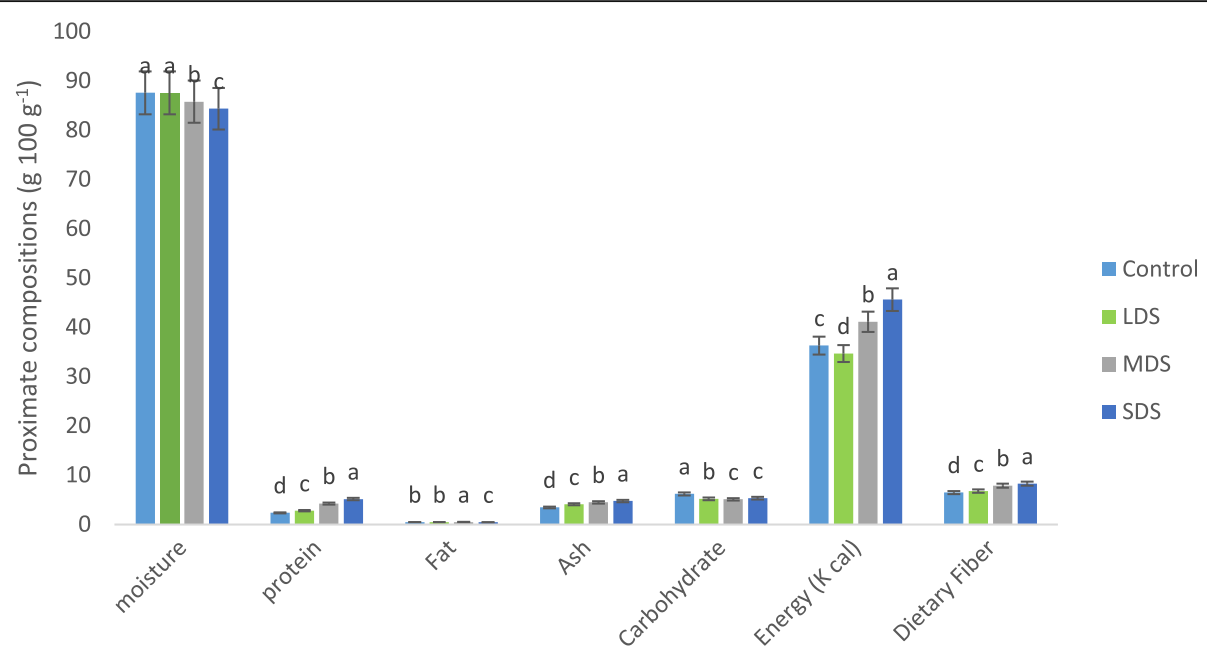

Fig. 1 Changes of proximate compositions (g $100 \mathrm{~g}^{-1}$ ) at four drought levels: Control (100\% FC), LDS (90\% FC), MDS (60\% FC), and SDS (30\% FC) in a selected $A$. tricolor genotype; $(n=3)$, letters mentioned in the bars are significantly varied by DMRT $(P<0.01)$

carotenoids, all the leaf pigments (Betacyanin, betaxanthin, betalain, chlorophyll $a$, chlorophyll $b$ and chlorophyll $a b$ content) were significantly and gradually reduced with the increase of the severity of drought stress (control > LDS $>$ MDS $>$ SDS). In LDS, MDS and SDS, betacyanin, betaxanthin, betalain, chlorophyll $a$, chlorophyll $b$ and chlorophyll $a b$ content were declined by $(0.5,2,1,3,2$ and $3 \%) ;(5,5$, $5,7,9$ and $8 \%)$ and $(8,9,9,12,12$ and $12 \%)$; respectively, over control condition (Fig. 7). Betacyanin, betaxanthin, betalain, chlorophyll $a$, chlorophyll $b$ and chlorophyll $a b$ content were the highest in control condition, whereas betacyanin, betaxanthin, betalain, chlorophyll $a$, chlorophyll $b$ and chlorophyll $a b$ content were the lowest in SDS.
Total carotenoids were significantly and remarkably increased with the increasing the severity of drought stress (control $<$ LDS $<$ MDS $<$ SDS). In LDS, MDS and SDS, total carotenoids were significantly and remarkably increased by 4,24 and $60 \%$, respectively over control condition (Fig. 7).

\section{Influence of betacarotene, vitamin C, TPC, TFC and TAC to drought stress}

Betacarotene, vitamin C content, TPC, TFC and TAC of $A$. tricolor were progressively influenced by drought stress Fig. 8. In this investigation, betacarotene, vitamin C content, total polyphenol content (TPC), total flavonoid content (TFC), total antioxidant capacity (TAC) $(\mathrm{DPPH})$ and $\mathrm{TAC}\left(\mathrm{ABTS}^{+}\right)$were significantly increased

\section{Proximate compositions}

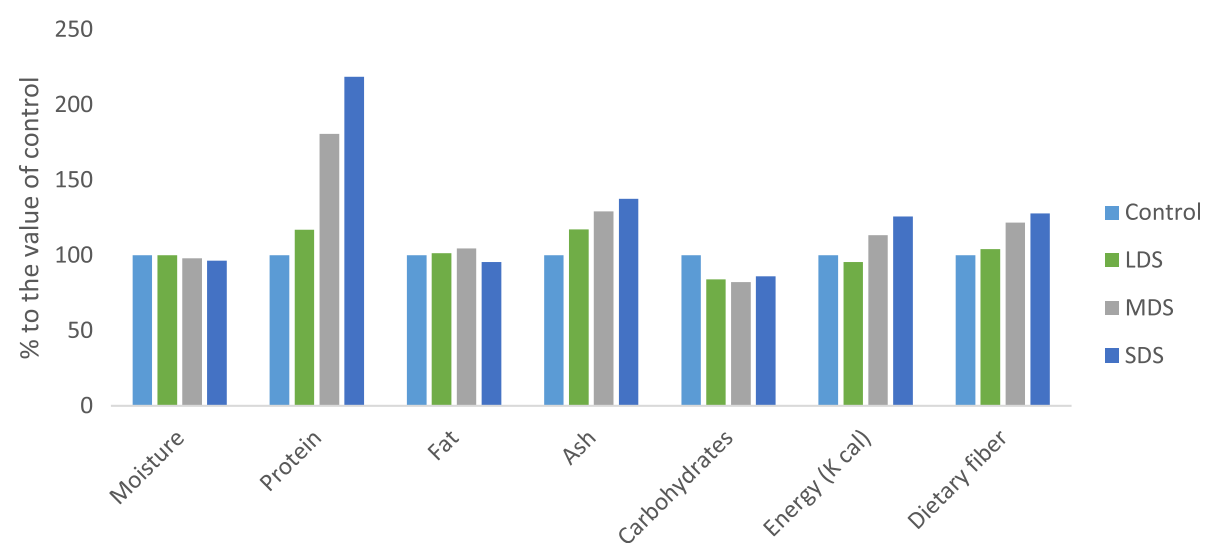

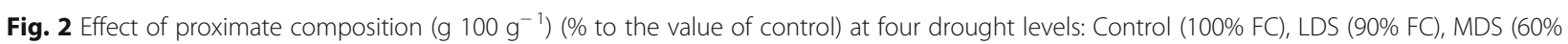
$\mathrm{FC})$, and SDS (30\% FC) in a selected A. tricolor genotype 


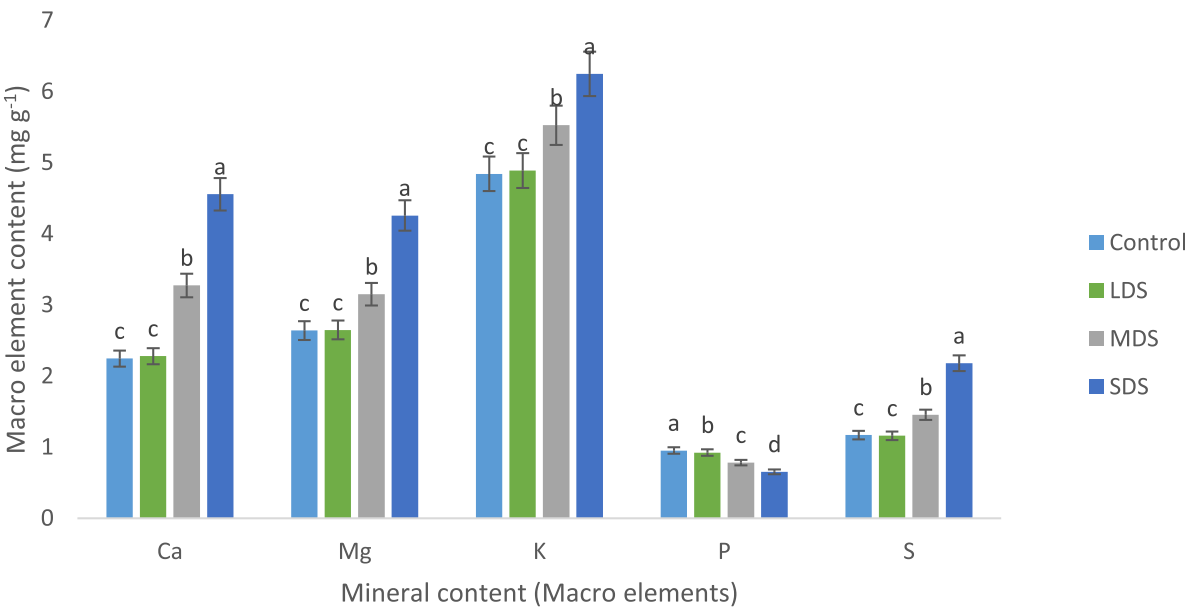

Fig. 3 Response of mineral content (Macro elements $\mathrm{mg} \mathrm{g}^{-1}$ ) at four drought levels: Control (100\% FC), LDS (90\% FC), MDS (60\% FC), and SDS $(30 \%$ FC) in a selected $A$. tricolor genotype; $(n=3)$, letters mentioned in the bars are significantly varied by DMRT $(P<0.01)$

with the increasing of the severity of drought stress in the order: control $<$ LDS $<$ MDS $<$ SDS. In LDS, MDS and SDS, betacarotene, vitamin $\mathrm{C}$ content, TPC, TFC, TAC (DPPH) and TAC $\left(\mathrm{ABTS}^{+}\right)$were augmented by $(8$, $42,11,19,9$ and $33 \%) ;(72,100,36,37,45$ and $56 \%)$ and (93, 63, 45, 60, 75 and 99\%); respectively, compared to control condition (Fig. 9). SDS condition had the highest betacarotene, vitamin $\mathrm{C}, \mathrm{TPC}, \mathrm{TFC}, \mathrm{TAC},(\mathrm{DPPH})$ and $\mathrm{TAC}\left(\mathrm{ABTS}^{+}\right)$, while the control condition exhibited the lowest betacarotene, vitamin $\mathrm{C}, \mathrm{TPC}, \mathrm{TFC}, \mathrm{TAC}(\mathrm{DPPH})$ and $\mathrm{TAC}\left(\mathrm{ABTS}^{+}\right)$.

Influence of drought stress on phenolics and flavonoids Results of retention time, $\lambda \max$, molecular ion, main fragment ions in $\mathrm{MS}^{2}$ and tentative compound identification for phenolic compounds are presented in Table 1.
The values of phenolic acids and flavonoids components of A tricolor genotype VA3 were separated though LC by comparing with masses of ion of standard flavonoids and phenolic acids and also by detecting the specific peaks of the corresponding components. A total of sixteen phenolic compounds were identified including six hydroxybenzoic acids, seven hydroxycinnamic acids and three flavonoids. Trans-cinnamic acid was newly identified phenolic acid in A. tricolor. However, an attempt was made for the first time to study the effect of drought stress in antioxidant enriched and high yield potential $A$. tricolor genotype VA3, in terms of sixteen phenolic acids and flavonoids. Within phenolic acids and flavonoids, hydroxybenzoic acids were identified as most abundant compounds in this genotype. Among hydroxybenzoic acids, salicylic acid was identified as one of the main

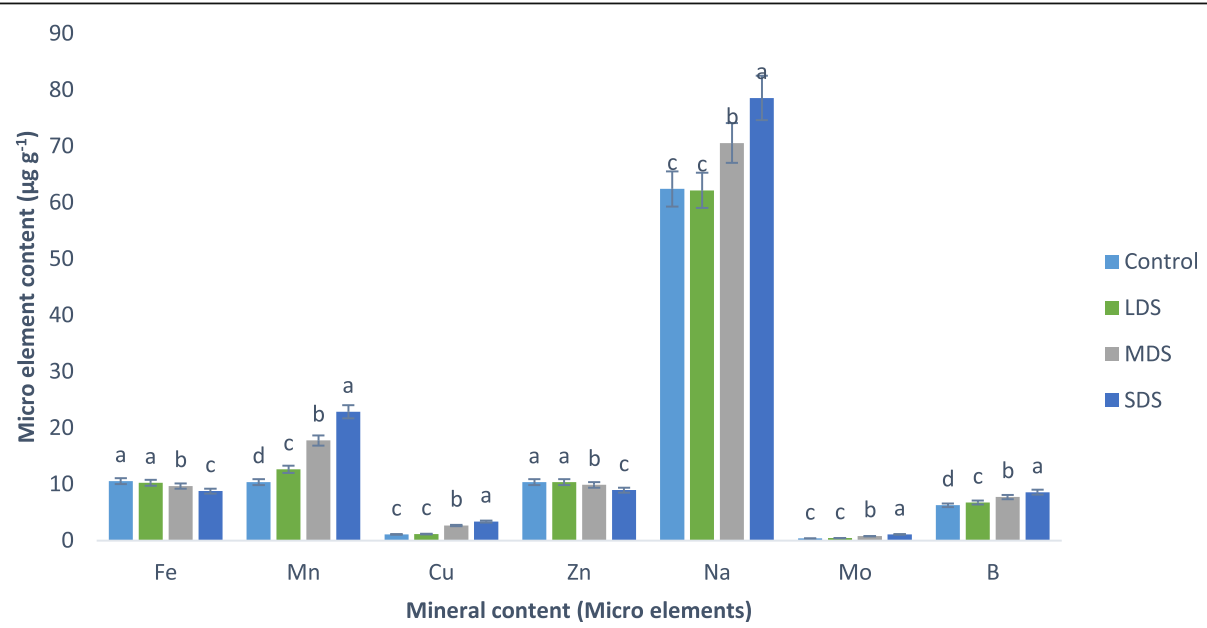

Fig. 4 Impact of mineral content (Micro elements $\mu \mathrm{g} \mathrm{g}^{-1}$ ) at four drought levels: Control (100\% FC), LDS (90\% FC), MDS (60\% FC), and SDS (30\% FC) in a selected $A$. tricolor genotype; $(n=3)$, letters mentioned in the bars are significantly varied by DMRT $(P<0.01)$ 


\section{Mineral content (Macro and micro elements)}

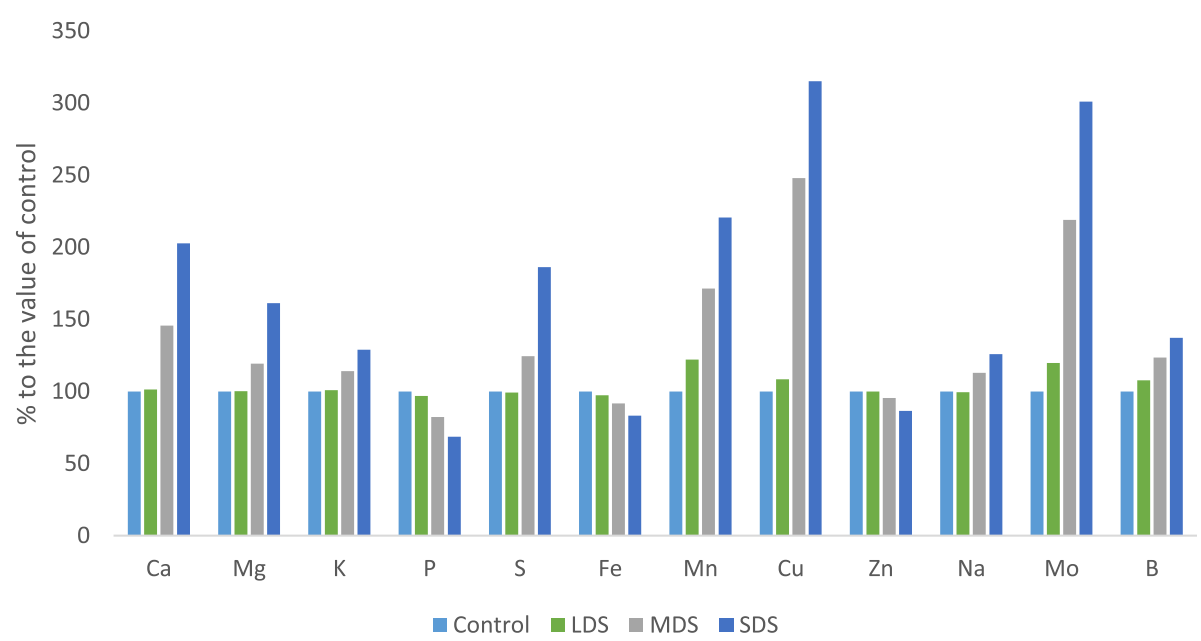

Fig. 5 Assessment of mineral contents (Macro and microelements, $\mathrm{mg} \mathrm{g}^{-1}$ and $\mu \mathrm{g} \mathrm{g}^{-1}$, respectively) (\% to the value of control) at four drought levels: Control (100\% FC), LDS (90\% FC), MDS (60\% FC), and SDS (30\% FC) in a selected A. tricolor genotype

phenolic acids followed by vanilic acid and gallic acid and $p$-hydroxybenzoic acid. Considering hydroxycinnamic acids, chlorogenic acid and Trans-cinnamic acid were the most abundant compound followed by $m$-coumaric acid. A good amount of caffeic acid, $p$-coumaric acid and ferulic acid were also identified in this genotype. In this investigation, the flavonoids, rutin (quercetin-3-rutinoside) and isoquercetin (quercetin-3-glucoside) were the most abundant in this genotype.

The hydroxybenzoic acid (Syringic acid and); the hydroxycinnamic acid (Ferulic acid) and three flavonoids, iso-quercetin, hyperoside and rutin had no significant differences in their compositions under control and LDS conditions, nevertheless, the composition of these acids were significantly increased from MDS to SDS. In

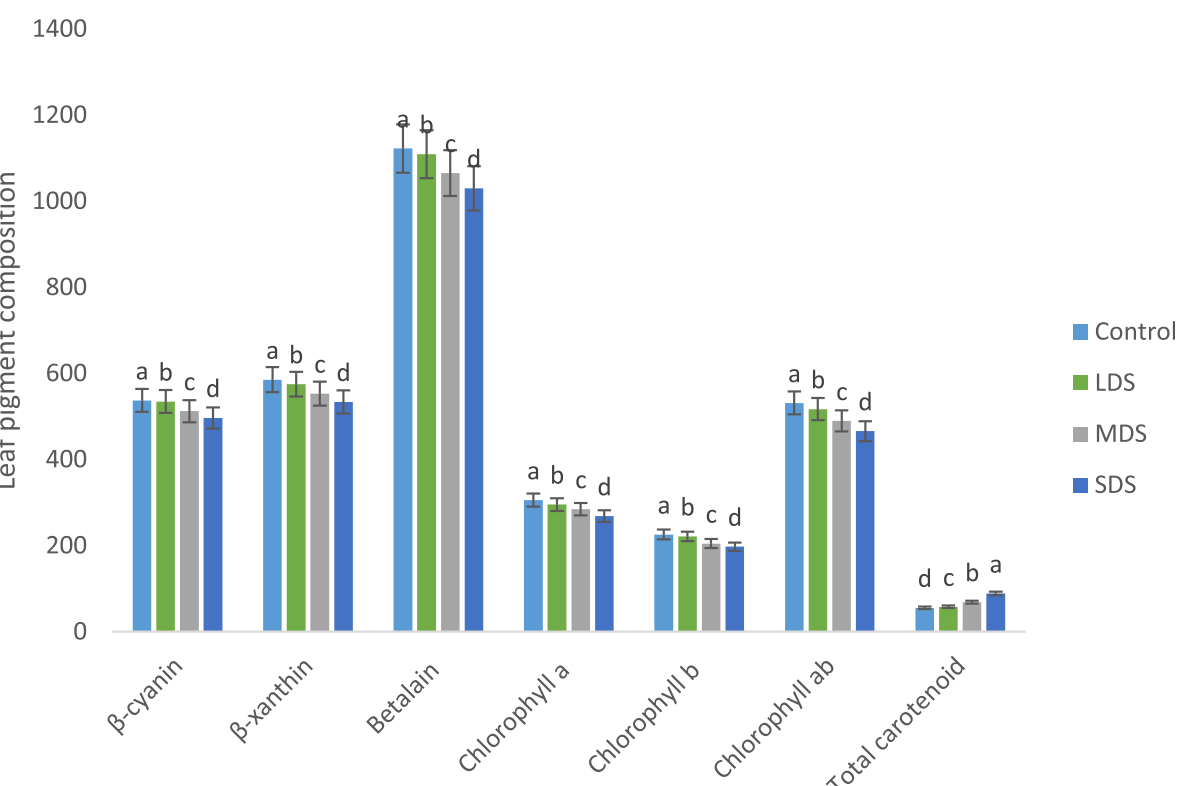

Fig. 6 Influence of Leaf pigments at four drought levels: Control (100\% FC), LDS (90\% FC), MDS (60\% FC), and SDS (30\% FC) in a selected A.

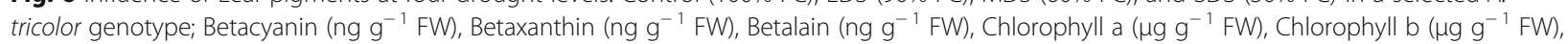

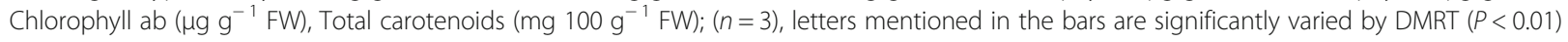




\section{Leaf pigments}

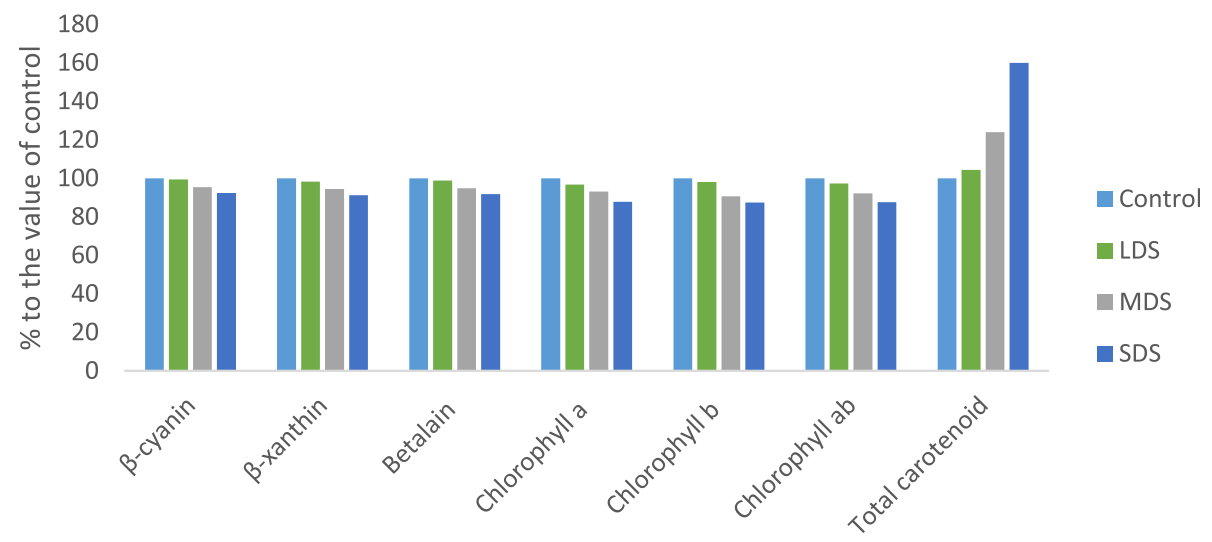

Fig. 7 Comparison of leaf pigments (\% to the value of control) at four drought levels: Control (100\% FC), LDS (90\% FC), MDS (60\% FC), and SDS (30\% FC) in a selected A. tricolor genotype; Betacyanin ( $\mathrm{ng} \mathrm{g}^{-1} \mathrm{FW}$ ), Betaxanthin ( $\mathrm{ng} \mathrm{g}^{-1} \mathrm{FW}$ ), Betalain ( $\mathrm{ng} \mathrm{g}^{-1} \mathrm{FW}$ ), Chlorophyll a ( $\mu \mathrm{gg} \mathrm{g} \mathrm{g}^{-1} \mathrm{FW}$ ), Chlorophyll b ( $\mu \mathrm{g} \mathrm{g}^{-1} \mathrm{FW}$ ), Chlorophyll ab ( $\left.\mathrm{gg} \mathrm{g}^{-1} \mathrm{FW}\right)$,Total carotenoids (mg $100 \mathrm{~g}^{-1} \mathrm{FW}$ )

MDS and SDS, these phenolic acids and flavonoids compositions were increased by $(41,53,8234$ and $22 \%)$ and (56, 111, 12174 and 43\%); respectively compared to control or LDS condition (Figs. 10, 11). Five hydroxybenzoic acids (Gallic acid, vanilic acid, $p$-hydroxybenzoic acid, salicylic acid and ellagic acid) and six hydroxycinnamic acid (Caffeic acid, chlorogenic acid, trans-cinnamic acid, $p$-coumaric acid, $m$-coumaric acid and sinapic acid) were remarkably increased with the increment of the severity of drought stress in the order: Control $<$ LDS $<$ MDS $<$ SDS. In LDS, MDS and SDS, these phenolic acids and flavonoids concentrations were increased by (19, 4, 7, 9 6, 8, 4, 8, 13, 31 and 22\%); (42, 32,
$23,19,42,26,27,105,109,47$ and $50 \%)$ and $(69,59,54$, $66,111,65,72,41,115,45,154,65$ and $60 \%$ ); respectively (Figs.10, 11).

\section{Discussion}

As leafy vegetables, A. tricolor leaves exhibited high moisture content. Nevertheless, it demonstrated a noble source of protein, dietary fiber, carbohydrates and ash. Moisture content was significantly reduced with the increment of drought stress in the following order: (control > LDS > MDS > SDS). As lower moisture contents of leaves ensured higher dry matter, the drought-stressed plant could be a promising source of dry matter

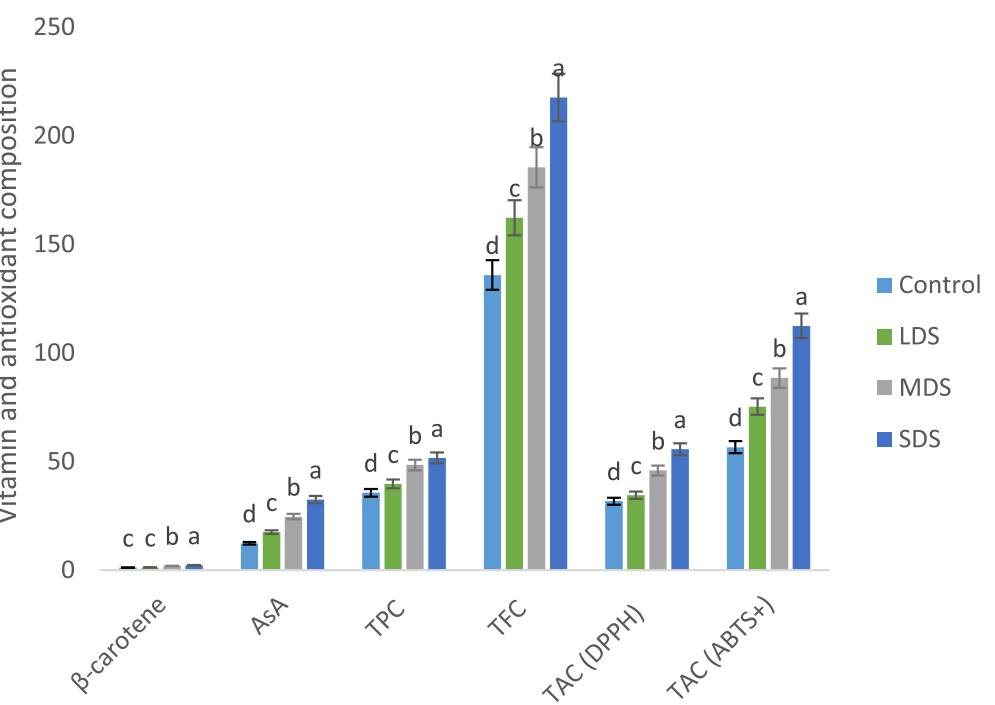

Fig. 8 Response of Betacarotene, Vitamin C, TPC, TFC and TAC at four drought levels: Control (100\% FC), LDS (90\% FC), MDS (60\% FC), and SDS

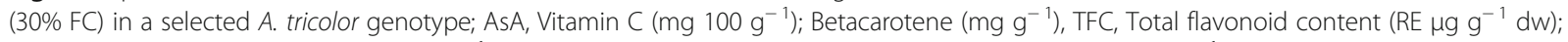
TPC, Total polyphenol content (GAE $\mu \mathrm{g} \mathrm{g}{ }^{-1} \mathrm{dw}$ ); TAC (ABTS ${ }^{+}$), Total antioxidant capacity (ABTS ${ }^{+}$) (TEAC $\mu \mathrm{g} \mathrm{g}{ }^{-1} \mathrm{dw}$ ); TAC (DPPH), Total antioxidant capacity (DPPH) (TEAC $\left.\mu \mathrm{g} \mathrm{g}^{-1} \mathrm{dw}\right) ;(n=3)$, letters mentioned in the bars are significantly varied by DMRT $(P<0.01)$ 


\section{Vitamins and antioxidant}

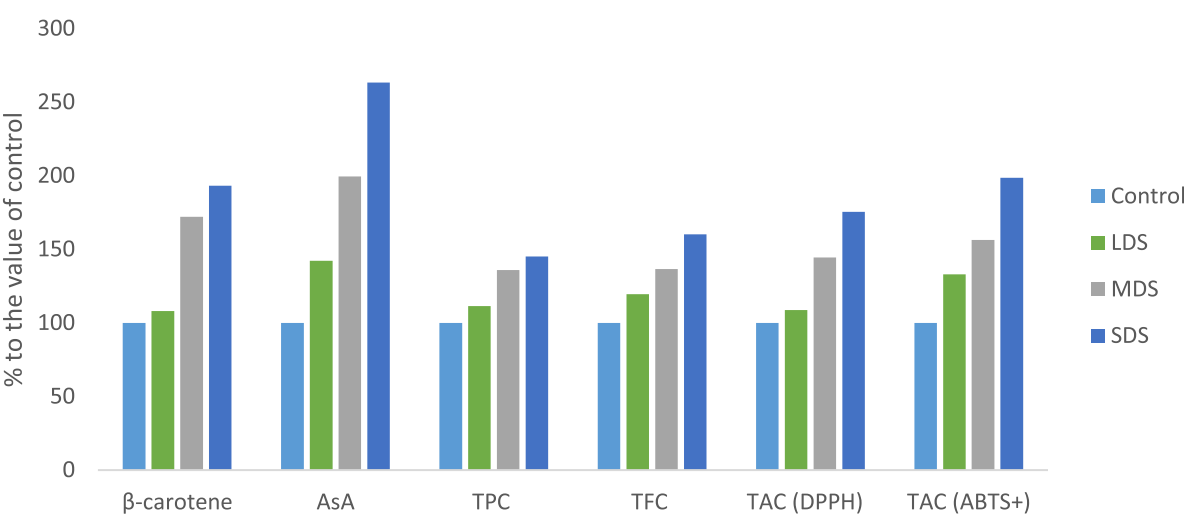

Fig. 9 Response of Vitamins, TFC, TPC and TAC, (\% to the value of control) at four drought levels: Control (100\% FC), LDS (90\% FC), MDS $(60 \% \mathrm{FC})$, and SDS (30\% FC) in a selected A. tricolor genotype; AsA, Vitamin C (mg $\left.100 \mathrm{~g}^{-1}\right)$; Betacarotene ( $\left.\mathrm{mg} \mathrm{g}^{-1}\right)$, TFC, Total flavonoid content (RE $\mu \mathrm{g} \mathrm{g}^{-1} \mathrm{dw}$ ); TPC, Total polyphenol content (GAE $\mu \mathrm{g} \mathrm{g} \mathrm{g}^{-1} \mathrm{dw}$ ); TAC (ABTS $)^{+}$, Total antioxidant capacity (ABTS ${ }^{+}$) (TEAC $\mu \mathrm{g} \mathrm{g}^{-1} \mathrm{dw}$ ) TAC (DPPH), Total antioxidant capacity (DPPH) (TEAC $\left.\mu \mathrm{g} \mathrm{g}^{-1} \mathrm{dw}\right)$

compared to control condition. In LDS, MDS and SDS, protein, ash and dietary fiber content were augmented by (17, 17 and $4 \%) ;(80,29$ and $21 \%)$ and $(118,38$ and $28 \%)$; respectively over control condition. However, Siracusa et al. [17] observed a decrease in protein content at drought stress to fully irrigated in buckwheat. The genotypic variances between two crops might be contributed for the different results. A. tricolor is the sources of protein for vegetarian and poor people of the third world countries. Dietary fiber has a significant role in palatability, digestibility and remedy of constipation [22]. MDS condition had the highest fat content, and the lowest fat content was observed under SDS condition. Fats are sources of omega- 3 and omega- 6 fatty acids. It helps in the digestion, absorption, and transport of fat-soluble vitamins A, D, E, and K. Sun et al. [34] observed similar results in sweet potato leaves where they mentioned that fat involved in the insulation of body organs and in the maintenance of body temperature and cell function. Control had the highest carbohydrates content and it was gradually decreased in the order: control $>$ LDS $>$ MDS = SDS, which was statistically similar to MDS and SDS, respectively. Carbohydrate content sharply declined with the severity of drought stress. As a leafy vegetable, the low carbohydrate content of amaranth leaves has no a substantial effect on the daily diet of human body. As regards energy balance, SDS exhibited remarkably higher calories compared to MDS, LDS and control conditions, while these variations have no remarkable impact on the daily diet of the human body, since very little amounts were consumed in the daily diet. Drought stress increased the protein, ash, energy, fat and dietary fiber content and reduced carbohydrate and moisture content of Amaranthus leaves. For this, Amaranthus leafy vegetable might be produced in a semi-arid and dry area in the world could be contributed as a noble source of dietary fiber and vegetarian protein in human diet.

Amaranth leaves are noble sources of minerals (macro and microelements). The mineral content of amaranth leaves was remarkably influenced by drought stress. Zinc and Fe content of A. tricolor are greater than that of the cassava leaves [35] and beach pea [36]. Similarly, Jimenez-Aguiar \& Grusak [37] reported high $\mathrm{Fe}, \mathrm{Mn}, \mathrm{Cu}$ and $\mathrm{Zn}$ (fresh weight basis) in different $A$. spp. including A. tricolor. They also reported that Amaranths had higher $\mathrm{Zn}$ content than black nightshade, spinach and kale; more $\mathrm{Fe}$ and $\mathrm{Cu}$ content than kale. $\mathrm{Ca}, \mathrm{Mg}, \mathrm{K}, \mathrm{S}$, $\mathrm{Cu}, \mathrm{Na}$ and Mo content were sharply and remarkably augmented with the severity of drought stress from MDS and SDS conditions showing the order: control = LDS $<$ MDS $<$ SDS. On the other hand, Hanson et al. [14] reported a decline in Ca content both in Choysum and Kailaan varieties from dry season to wet season trial. SDS exhibited the highest $\mathrm{Ca}, \mathrm{K}, \mathrm{S}, \mathrm{Mg}, \mathrm{Mn}, \mathrm{Na}, \mathrm{Cu}$, Mo and $\mathrm{B}$ content, while control or LDS condition had the lowest $\mathrm{Ca}, \mathrm{S}, \mathrm{K}, \mathrm{Mg}, \mathrm{Cu}, \mathrm{Mn}, \mathrm{Mo}, \mathrm{Na}$ and $\mathrm{B}$ content. In contrast, control or LDS condition had the highest $\mathrm{Zn}, \mathrm{P}$, and Fe content and SDS exerted the lowest P, Zn and Fe content. Likewise, Hanson et al. [14] recorded a decline in $\mathrm{Fe}$ content of Choysum variety, whereas they reported a sharp increment in Kailaan variety from dry season to wet season trial. Moreover, Hanson et al. [14] recorded a remarkable increment in $\mathrm{Zn}$ content both in Kailaan and Choysum variety from dry season to wet season trial. Except P, Fe and Zn, all the mineral content were progressively raised with the increment of drought stress, whereas, $\mathrm{Zn}, \mathrm{Fe}$ and $\mathrm{P}$ were sharply declined with the increment of drought stress. Therefore, A. tricolor cultivated in a drought-stressed area specifically in 


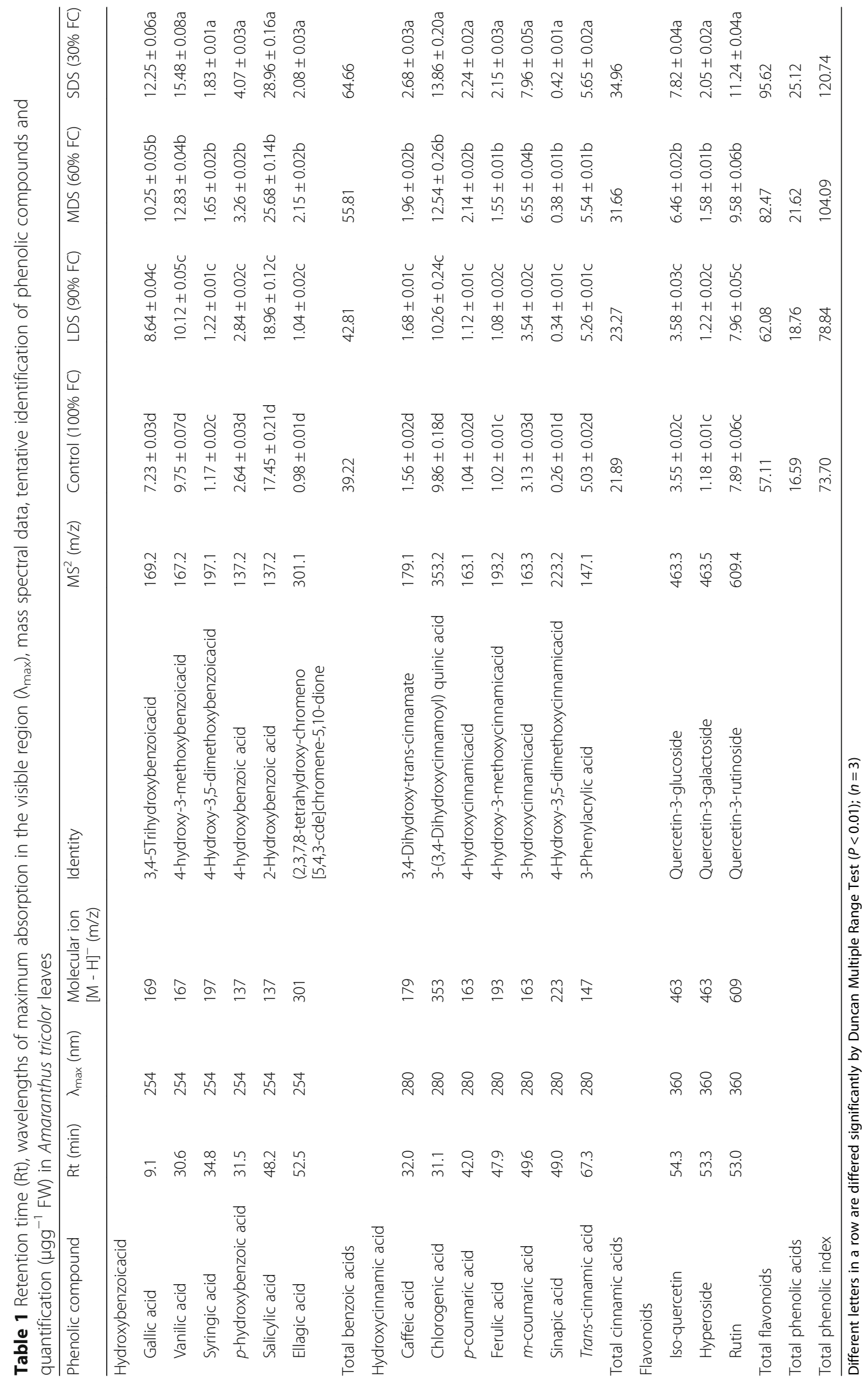




\section{Hydroxybenzoic acid}

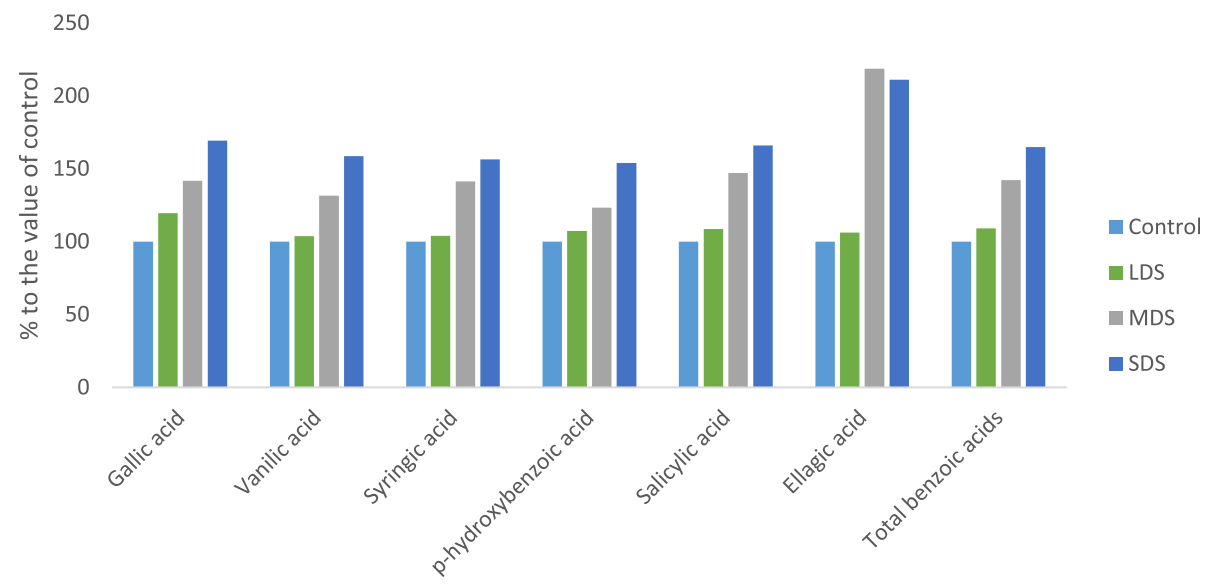

Fig. 10 Changes of hydroxybenzoic acid compositions ( $\mu \mathrm{g} \mathrm{g} \mathrm{g}^{-1} \mathrm{FW}$ ) (\% to the value of control) at four drought levels: Control (100\% FC), LDS ( $90 \%$ FC), MDS (60\% FC), and SDS (30\% FC) in a selected A. tricolor genotype

semi-arid and drought-prone area could be contributed as a noble source of minerals in the daily diet of human body related to usual farming practices.

Leaf pigments of $A$. tricolor were statistically influenced by drought stress. Except total carotenoids, all the leaf pigments (Betacyanin, betaxanthin, betalain, chlorophyll $a$, chlorophyll $b$ and chlorophyll $a b$ content) were significantly and gradually reduced with the increasing the severity of drought stress (control $>$ LDS $>$ MDS $>$ SDS). Likewise, Hsu and Kao [38] reported a decline in chlorophyll content with the increment of drought severity. They also stated that drought stress influenced growth and development of plant through osmotic stress, declining the water potential, reducing stomatal conductivity which limits $\mathrm{CO}_{2}$ influx to leaves and unfavorable $\mathrm{CO}_{2} / \mathrm{O}_{2}$ ratio in chloroplasts, decreasing photosynthesis.

Betacarotene, vitamin C content, TPC, TFC and TAC of A. tricolor were progressively influenced by drought stress. In this investigation, betacarotene, vitamin $\mathrm{C}$ content, total polyphenol content (TPC), total flavonoid content (TFC), total antioxidant capacity (TAC) (DPPH) and $\mathrm{TAC}\left(\mathrm{ABTS}^{+}\right)$were significantly increased with the increase of the severity of drought stress in the order: control $<\mathrm{LDS}<\mathrm{MDS}<\mathrm{SDS}$. SDS condition had the highest betacarotene, vitamin $\mathrm{C}, \mathrm{TPC}$, TFC, TAC, $(\mathrm{DPPH})$ and $\mathrm{TAC}\left(\mathrm{ABTS}^{+}\right)$, while the control condition exhibited lowest betacarotene, vitamin C, TPC, TFC, TAC (DPPH) and TAC $\left(\mathrm{ABTS}^{+}\right)$. Hanson et al. [14]

\section{Hyrdoxycinnamic acid and flavonoids}

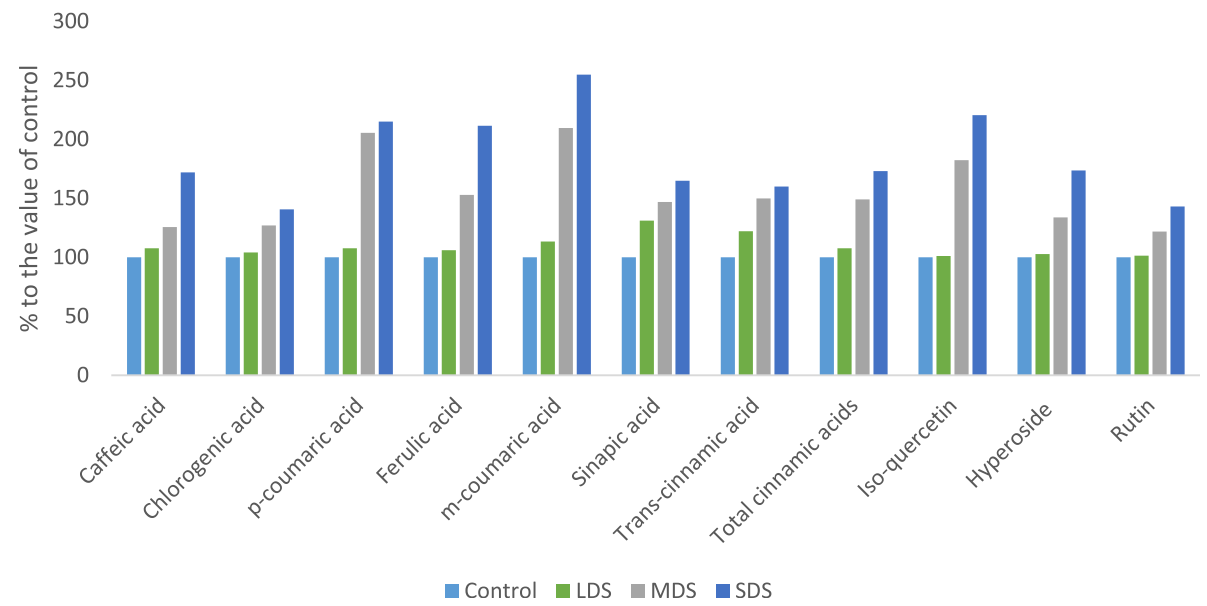

Fig. 11 Changes of hydroxycinnamic acid and flavonoid compositions ( $\mu \mathrm{g} \mathrm{g}^{-1} \mathrm{FW}$ ) (\% to the value of control) at four drought levels: Control $(100 \%$ FC), LDS ( $90 \%$ FC), MDS (60\% FC), and SDS (30\% FC) in a selected A. tricolor genotype 
reported an increase in betacarotene content of Choysum variety. In contrast, they reported a declining trend in betacarotene content of Kailaan variety and reduction in vitamin $\mathrm{C}$ content in both varieties from dry to wet season trial. The reason for reduction might be due to the genotypic variations in two different crops. Likewise, Gharibi et al. [18] in Achillea species and Siracusa et al. [17] in buckwheat, reported increment in antioxidant activity, polyphenol and flavonoid content with the severity of drought stress. The ameliorate response of betacarotene content with the severity of drought stress was also reported in Choysum varieties in dry season trial [14], and in perennial herbaceous [15]. Sarker and Oba [39] observed increase in betacarotene content with the severity of salt stress. Siracusa et al. [17] reported an increment of TPC, TFC in buckwheat with increasing the drought stress. Garibi et al. [18] also reported the enhancing response of TPC, TFC and antioxidant activity in Achillea species with the increment of drought stress.

A total of sixteen phenolic compounds were identified including six hydroxybenzoic acids, seven hydroxycinnamic acids and three flavonoids. Trans-cinnamic acid was newly identified phenolic acid in A. tricolor. Khanam \& Oba [40] in red and green amaranths and Khanam et al. [33] in eight different leafy vegetables including amaranths described rest fifteen phenolic acids and flavonoids with normal cultivation practices. However, an attempt was made for the first time to study the effect of drought stress in high yielding and high antioxidant containing A. tricolor cultivar VA3, in terms of sixteen phenolic acids and flavonoids. Gallic acid, vanilic acid and $p$-hydroxybenzoic acid content of the genotype VA3 under control condition were higher than A. tricolor genotypes that reported by Khanam et al. [33]. Considering hydroxycinnamic acids, chlorogenic acid and trans-cinnamic acid were the most abundant compound followed by $m$-coumaric acid. A good amount of caffeic acid, $p$-coumaric acid and ferulic acid were also identified in this genotype. Under control condition, chlorogenic acid, caffeic acid and $m$-coumaric acid of this genotype was higher than $A$. tricolor genotypes reported by Khanam et al. [33]. In plant tissues, phenylalanine produced widely dispersed phenolic acids i. e., hydroxycinnamic acids [41]. The most common forms of flavonoids are glycoside derivatives even though these compounds occasionally occur as a glycone in plants. Flavonoids represent $60 \%$ of total dietary phenolic compounds [42]. In plants, most predominant flavonoids are flavonols and the most prevalent naturally occurring flavonols are glycosides of quercetin [42]. We observed that isoquercetin (quercetin-3-glucoside) and rutin (quercetin-3-rutinoside) were the most abundant favonoids in VA3. Our study demonstrated that VA3 revealed higher rutin (quercetin-3-rutinoside) content at normal cultural practices compared to A. tricolor genotypes reported by Khanam et al. [33]. All the phenolic acids and flavonoids had the lowest concentrations under control condition, whereas these acids exhibited the highest concentrations under SDS condition. Hence, A. tricolor cultivated in a drought-stressed area specifically in the semi-arid and drought-prone area could be contributed as a noble source of minerals and bioactive compounds, phenolics and flavonoid content and antioxidant activity in the daily diet of human body related to usual farming practices.

\section{Conclusions}

In this study, antioxidant enriched and high yield potential A. tricolor genotype VA3 was selected from our germplasm collection and evaluated for nutritional and bioactive compounds, phenolic acids, flavonoids and antioxidant capacity under 4 irrigation regimes. Trans-cinnamic acid was newly identified phenolic acid in $A$. tricolor. Drought stress resulted in significant increment in protein, ash, energy, dietary fiber, $\mathrm{K}, \mathrm{S}, \mathrm{Ca}, \mathrm{Mn}, \mathrm{Mg}$, $\mathrm{Na}, \mathrm{Cu}, \mathrm{Mo}$ and $\mathrm{B}$ content, total carotenoids, betacarotene, vitamin $\mathrm{C}$, TAC (DPPH), TFC, TPC and TAC $\left(\mathrm{ABTS}^{+}\right)$, sixteen phenolic acids and flavonoids. All the nutritional and bioactive compounds, phenolics, flavonoids and antioxidant capacity of $A$. tricolor leaves was very high under MDS and SDS condition, in comparison to control condition, that could be contributed as valuable food sources for human diets and health benefit. Nutritional and bioactive compounds, phenolics, flavonoids might be played a vital role in scavenging ROS and would be beneficial for human nutrition by serving as good antioxidants and antiaging sources in human health benefit. Moreover, A. tricolor cultivated under drought stress could be contributed as a quality product of nutritional and bioactive compounds, phenolics, flavonoids and antioxidants. Based on the results reported farmers of semi-arid and dry areas of the world could be able to grow amaranth as an alternative crop.

\footnotetext{
Abbreviations

AAS: Atomic absorption spectrophotometry; $\mathrm{ABTS}^{+}$: 2,2'-azino-bis-(3ethylbenzothiazoline-6-sulphonic acid); AEZ: Agro-ecological zone; AOAC: Association of analytical communities; AsA: vitamin C; ASAE: American society of association executives; B: Boron; Ca: Calcium; Cu: Copper; DHA: Dehydroascorbate; DPPH: 2,2-diphenyl-1-picrylhydrazyl;

DTT: Dithiothreitol; dw: Dry weight; FC: Field capacity; Fe: Iron; FW: Fresh weight; $\mathrm{H}_{2} \mathrm{SO}_{4}$ : Sulphuric acid; $\mathrm{HClO}_{4}$ : Perchloric acid; $\mathrm{HNO}_{3}$ : Nitric acid; HPLC-UV: High performance liquid chromatography-ultra violetISOInternational organization for standardization; K: Potassium; LC-MS-ESI: Liquid chromatography-mass spectroscopy-electrospray ionization; LDS: Low drought stress; MDS: Moderate drought stress; Mg: Magnesium; Mn: Manganese; Mo: Molybdenum; Na: Sodium; $\mathrm{NaOH}$ : Sodium hydroxide; P: Phosphorus; ROS: Reactive oxygen species; S: Sulphur; SDS: Severe drought stress; TAC: Total antioxidant capacity; TFC: total flavonoid content; TPC: Total polyphenol content; Zn: Zinc
} 


\section{Acknowledgements}

None.

\section{Funding}

No funding was received.

\section{Availability of data and materials}

All data generated or analyzed during this study are included in this article and available from the corresponding author on reasonable request.

\section{Authors' contributions}

US conceptualized and conducted the experiments, analyzed the data, helped with the experimental design, and prepared and revised the manuscript. SO conceptualized the experiments and helped with its conduct, experimental design, and revised the manuscript. Both authors read and approved the final manuscript.

\section{Ethics approval and consent to participate} Not applicable.

\section{Consent for publication}

Not applicable.

\section{Competing interests}

The authors declare that they have no competing interests.

\section{Publisher's Note}

Springer Nature remains neutral with regard to jurisdictional claims in published maps and institutional affiliations.

Received: 28 March 2018 Accepted: 15 October 2018

Published online: 26 October 2018

\section{References}

1. Dusgupta N, De B. Antioxidant activity of some leafy vegetables of India: a comparative study. Food Chem. 2007:101:471-4.

2. Repo-Carrasco-Valencia R, Hellstrom JK, Pihlava JM, Mattila PH. Flavonoids and other phenolic compounds in Andean indigenous grains: quinoa (Chenopodium quinoa), kaniwa (Chenopodium pallidicaule) and kiwicha (Amaranthus caudatus). Food Chem. 2010;120:128-33.

3. Isabelle M, Lee BL, Lim MT, Koh WP, Huang D, Ong CN. Antioxidant activity and profiles of common fruits in Singapore. Food Chem. 2010;123:77-84.

4. Steffensen SK, Rinnan A, Mortensen AG, Laursen B, Troiani RM, Noellemeyer EJ, Janovska D, Dusek K, Delano-Frier J, Taberner A, Christophersen C, Inge S, Fomsgaard IS. Variations in the polyphenol content of seeds of field grown Amaranthus genotypes. Food Chem. 2011;129:131-8.

5. Venskutonis PR, Kraujalis P. Nutritional components of amaranth seeds and vegetables: a review on composition, properties, and uses. Comp Rev Food Sci Food Saf. 2013;12:381-412.

6. Azooz MM, Ismail AM, Abou-Elhamd MF. Growth, lipid peroxidation and antioxidant enzyme activities as a selection criterion for the salt tolerance of three maize cultivars grown under salinity stress. Intl J Agric Biol. 2009;11:21-6.

7. Blokhina O, Virolainen E, Fagerstedt KV. Antioxidants, oxidative damage and oxygen deprivation stress. Ann Bot. 2003;91:179-94.

8. Romani A, Pinelli P, Galardi C, Sani G, Cimato A, Heimler D. Polyphenols in greenhouse and open-air-grown lettuce. Food Chem. 2002;79:337-42.

9. Iwai K. Antidiabetic and antioxidant effects of polyphenols in brown alga Echlonia stolonifera in genetically diabetic KK-ay mice. Plant Foods Hum Nutr. 2008;63:163-9.

10. Liu F, Stutzel H. Leaf water relations of vegetable amaranth (Amaranthus spp.) in response to soil drying. European J Agron. 2002;16:137-50.

11. Hura T, Hura K, Grzesiak M, Rzepka A. Effect of long-term drought stress on leaf gas exchange and fluorescence parameters in C3 and C4 plants. Acta Physiol Plant. 2007;29:103-13.

12. Rana JC, Pradheep K, Yadav SK, Verma VD, Sharma PC. Durga: a new variety of grain amaranth for cultivation in hill regions. Indian Farm. 2007:57:27-8.

13. Selmar D, Kleinwachter M. Influencing the product quality by deliberately applying drought stress during the cultivation of medicinal plants. Ind Crop Prod. 2013:42:558-66.
14. Hanson P, Yang RY, Chang LC, Ledesma L, Ledesma D. Carotenoids, vitamin $C$, minerals, and total glucosinolates in choysum (Brassica rapa cv g. parachinensis) and kailaan (B. oleracea Alboglabra group) as affected by variety and wet and dry season production. J Food Compos Anal. 2011;24:950-62

15. Hillova D, Takacsova M, Lichtnerova H. Stomatal response to water stress in herbaceous perennials. PI Urban Areas Landscape. 2014. https://doi.org/10. 15414/2014.9788055212623.52-56.

16. Stagnari F, Angelica G, Mychele P. Water stress and crop plant: a sustainable approach. In: Ahamad P, editor. Drought stress effect on crop quality West Sussex. UK: Wiley; 2016. p. 375-87.

17. Siracusa L, Gresta F, Sperlinga E, Ruberto G. Effect of sowing time and soil water content on grain yield and phenolic profile of four buckwheat (Fagopyrum esculentum Moench.) varieties in a Mediterranean environment. J Food Compos Anal. 2017:62:1-7.

18. Gharibi S, Tabatabaei BES, Saeidi G, Goli SAH. Effect of drought stress on total phenolic, lipid peroxidation, and antioxidant activity of Achillea species. Appl Biochem Biotechnol. 2016;178:796-809.

19. Sarker U, Islam MT, Rabbani MG, Oba S. Genotypic variability for nutrient, antioxidant, yield and yield contributing traits in vegetable amaranth. J Food Agri Environ. 2014;12:168-74

20. Sarker U, Islam MT, Rabbani MG, Oba S. Variability, heritability and genetic association in vegetable amaranth (Amaranthus tricolor). Span J Agric Res. 2015a;13:1-8 https://doi.org/10.5424/sjar/2015132-6843.

21. Sarker U, Islam MT, Rabbani MG, Oba S. Genotype variability in composition of antioxidant vitamins and minerals in vegetable amaranth. Genetika. 2015b;47:85-96.

22. Sarker U, Islam MT, Rabbani MG, Oba S. Genetic variation and interrelationship among antioxidant, quality and agronomic traits in vegetable amaranth. Turk J Agric For. 2016;40:526-35.

23. Sarker U, Islam MT, Rabbani MG, Oba S. Genotypic diversity in vegetable amaranth for antioxidant, nutrient and agronomic traits. Indian J Genet PI Breed. 2017;77:173-6.

24. Sarker U, Islam MT, Rabbani MG, Oba S. Variability in total antioxidant capacity, antioxidant leaf pigments and foliage yield of vegetable amaranth. J Integrative Agric. 2018a;17:1145-53.

25. Sarker U, Islam MT, Rabbani MG, Oba S. Phenotypic divergence in vegetable amaranth for total antioxidant capacity, antioxidant profile, dietary fiber, nutritional and agronomic traits. Acta Agric Scandinavica Section B-Soil PI Sci 2018b;68:67.

26. Sarker U, Islam MT, Rabbani MG, Oba S. Antioxidant leaf pigments and variability in vegetable amaranth. Genetika. 2018c;50:209-20.

27. ASAE. ASAE standard: ASAE S352.1. Moisture measurement-grains and seeds. Michigan: ASAE, St. Joseph; 1983

28. AOAC (Association of Analytical Chemists) (2000). Official methods of analysis $\left(17^{\text {th }}\right.$ Ed.). Gaithersburg, MD, USA: AOAC International.

29. ISO (International Standards Organization). Organization for Standardization. ISO 5498:1981. Determination of crude fiber content, general method. In: Geneva. Switzerland: ISO; 1981.

30. Colonna E, Rouphael Y, Barbieri G, Pascale D. Nutritional quality of ten leafy vegetables harvested at two light intensities. Food Chem. 2016;199:702-10.

31. Sarker U, Oba S. Response of nutrients, minerals, antioxidant leaf pigments, vitamins, polyphenol, flavonoid and antioxidant activity in selected vegetable amaranth under four soil water content. Food Chem. 2018d;252:72-83.

32. Sarker U, Oba S. Drought stress effects on growth, ROS markers, compatible solutes, phenolics, flavonoids, and antioxidant activity in Amaranthus tricolor. Appl Biochem Biotechnol. 2018e. https://doi.org/10.1007/s12010-018-2784-5.

33. Khanam UKS, Oba S, Yanase E, Murakami Y. Phenolic acids, flavonoids and total antioxidant capacity of selected leafy vegetables. J Functional Foods. 2012:4:979-87.

34. Sun H, Mu T, Xi L, Zhang M, Chen J. Sweet potato (Ipomoea batatas L.) leaves as nutritional and functional foods. Food Chem. 2014;156:380-9.

35. Madruga MS, Camara FS. The chemical composition of "Multimistura" as a food supplement. Food Chem. 2000;68:41-4.

36. Shahidi F, Chavan UD, Bal AK, McKenzie DB. Chemical composition of beach pea (Lathyrus maritimus L.) plant parts. Food Chem. 1999;64:39-44.

37. Jimenez-Aguilar DM, Grusak MA. Minerals, vitamin C, phenolics, flavonoids and antioxidant activity of Amaranthus leafy vegetables. J Food Compos Anal. 2017;58:33-9. 
38. Hsu SY, Kao CH. Differential effect of sorbitol and polyethylene glycol on antioxidant enzymes in rice leaves. J Plant Growth Regul. 2003;39:83-90.

39. Sarker U, Oba S. Augmentation of leaf color parameters, pigments, vitamins, phenolic acids, flavonoids and antioxidant activity in selected Amaranthus tricolor under salinity stress. Sci Rep. 2018f;8:12349. https://doi.org/10.1038/ s41598-018-30897-6

40. Khanam UKS, Oba S. Bioactive substances in leaves of two amaranth species, Amaranthus tricolor and A. hypochondriacus. Canadian J PI Sci. 2013;93:47-58

41. Robbins RJ. Phenolic acids in foods: an overview of analytical methodology. J Agril Food Chem. 2003;51:2866-87.

42. Harborne JB, Williams CA. Advances in flavonoid research since 1992. Phytochemistry. 2000;55:481-504.

Ready to submit your research? Choose BMC and benefit from:

- fast, convenient online submission

- thorough peer review by experienced researchers in your field

- rapid publication on acceptance

- support for research data, including large and complex data types

- gold Open Access which fosters wider collaboration and increased citations

- maximum visibility for your research: over $100 \mathrm{M}$ website views per year

At BMC, research is always in progress.

Learn more biomedcentral.com/submissions 